\title{
Continued increase in the prevalence of asthma and atopy
}

\author{
S H Downs, G B Marks, R Sporik, E G Belosouva, N G Car, J K Peat
}

\begin{abstract}
Aims-To describe the change in the prevalence of wheeze, diagnosed asthma, and atopy in Wagga Wagga, NSW, Australia, between 1992 and 1997, and to compare this to the increase in prevalence reported between 1982 and 1992.

Methods-A cross sectional study of the prevalence of respiratory symptoms and atopy in schoolchildren aged 8-11 years $(n=1016$, response rate $71 \%)$ in 1997 compared with studies of similar design in 1992 (response rate 83\%, $n=850$ ) and 1982 (response rate $88 \%, n=769$ ). Main outcome measures were respiratory symptoms measured by parent completed questionnaire and atopy measured by skin prick tests.
\end{abstract}

Results-Between 1992 and 1997, the prevalence of wheeze increased by $5.1 \%$ (95\% CI 1.2 to 9.0$)$, asthma diagnosis by $8.1 \%(95 \%$ CI 3.8 to 12.4$)$, and atopy by $6.7 \%(95 \%$ CI 2.2 to 11.2$)$. Similar increases in prevalence had been found between 1982 and 1992.

Conclusions-The prevalence of wheeze, asthma diagnosis, and atopy in Wagga Wagga has continued to increase.

(Arch Dis Child 2001;84:20-23)

Keywords: asthma; atopy; prevalence

H Downs

G B Mark

R Sporik

E G Belosouva

School of Biomedical Sciences, Charles

Sturt University, NSW, Australia

N G Car

New Children's

Hospital, Westmead,

NSW, Australia

$\mathrm{J}$ K Peat

Correspondence to:

Ms Downs

shd@mail.med.usyd.edu.au

Accepted 25 July 2000
Wales. ${ }^{7}$ In Wagga Wagga, parent reported "wheeze in the past 12 months" increased by $6.6 \%$ and asthma diagnosis by $17.6 \%$. There was also a small but non-significant increase in the prevalence of atopy. In 1997, we undertook a further cross sectional study in Wagga Wagga to determine whether there had been any further change in the prevalence of wheeze, asthma diagnosis, and atopy since 1992.

\section{Methods}

POPULATIONS

The population sampled was primary school children in Wagga Wagga in 1997. The results were compared to those from similar studies in Wagga in 1992 and $1982 .{ }^{7}$ Wagga is an inland town (population approximately 55000 ) in New South Wales, Australia $\left(147^{\circ} \mathrm{E}, 35^{\circ} \mathrm{S}\right)$. The cross sectional studies were undertaken during the winters of 1982 (June), 1992 (June), and 1997 (July).

Two thirds of the schools in Wagga Wagga were randomly selected for study in 1982 and two thirds of schools for the study in 1992. Eleven of the 12 primary schools in the western half of Wagga were selected for the study in 1997. The twelfth primary school was excluded because estimated intake of pupils for school years 3, 4, and 5 was less than 20 .

Approval for the studies was given by the Human Ethics Committee of the University of Sydney. Consent was obtained from the NSW Department of School Education, the Catholic Education Office, and each school principal. Parents of children from school years 3 and 4 (aged 8-10 years) in 1982 and school years 3, 4, and 5 (aged 8-11 years) in 1992 and 1997 were sent a letter describing the study and requesting consent for their child's participation. The study includes all children whose parents gave written consent.

\section{QUESTIONNAIRE}

Parents completed questionnaires about their child. The study questionnaires were versions of the Children's Respiratory Questionnaire developed and validated by the Institute of

Table 1 Change in prevalence (\%) of symptoms

\begin{tabular}{|c|c|c|c|c|c|c|}
\hline \multirow[b]{2}{*}{ Symptoms } & \multirow{2}{*}{$\begin{array}{l}1982 \% \\
(n=769)\end{array}$} & \multirow{2}{*}{$\begin{array}{l}1992 \% \\
(n=850)\end{array}$} & \multirow{2}{*}{$\begin{array}{l}1997 \% \\
(n=1016)\end{array}$} & \multicolumn{3}{|c|}{ Percent increase ( $95 \%$ CI) } \\
\hline & & & & 1982-92 & $1992-97$ & $1982-97$ \\
\hline Ever wheezed & 23.9 & 36.9 & 42.3 & $13.0(8.5$ to 17.5$)$ & $5.3(0.1$ to 9.8$)$ & $18.4(14.1$ to 22.6$)$ \\
\hline Wheezed in the past 12 months & 15.5 & 22.1 & 27.2 & $6.6(2.8$ to 10.4$)$ & $5.1(1.2$ to 9.0$)$ & $11.7(8.0$ to 15.5$)$ \\
\hline $\begin{array}{l}\text { Four or more wheezing episodes in past } 12 \\
\text { months }\end{array}$ & 5.2 & 13.7 & 16.9 & 8.5 (5.7 to 11.3 ) & $3.2(-0.1$ to 6.5$)$ & $11.7(8.8$ to 14.5$)$ \\
\hline Diagnosed asthma & 12.9 & 30.5 & 38.6 & $17.6(13.5$ to 21.6$)$ & $8.1(3.8$ to 12.4$)$ & $12.9(10.5$ to 15.3$)$ \\
\hline Ever had asthma medicine & 8.5 & 35.0 & 46.0 & $26.5(22.8$ to 30.3$)$ & $10.9(6.4$ to 15.4$)$ & $8.5(6.5$ to 10.5$)$ \\
\hline Has ever had hay fever or nasal allergies & 22.5 & 43.7 & 44.0 & $21.2(16.6$ to 25.8$)$ & $-0.3(-4.3$ to 4.8$)$ & $21.5(17.2$ to 25.7$)$ \\
\hline Natural mother or father has had asthma & 25.0 & 30.8 & 41.9 & $5.8(1.3$ to 10.2$)$ & $11.1(6.6$ to 15.7$)$ & $16.9(12.4$ to 21.4$)$ \\
\hline
\end{tabular}


Table 2 Change in prevalence (\%) of atopy

\begin{tabular}{|c|c|c|c|c|c|c|}
\hline \multirow[b]{2}{*}{ Allergen } & \multirow{2}{*}{$\begin{array}{l}1982 \% \\
(n=769)\end{array}$} & \multirow{2}{*}{$\begin{array}{l}1992 \% \\
(n=850)\end{array}$} & \multirow{2}{*}{$\begin{array}{l}1997 \% \\
(n=962)\end{array}$} & \multicolumn{3}{|c|}{ Percent increase $(95 \% \mathrm{CI})$} \\
\hline & & & & $1982-92$ & $1992-97$ & $1982-97$ \\
\hline $\begin{array}{l}\text { At least one of } D \text { farinae, cat, rye grass, plantain, } \\
\text { Alternaria }\end{array}$ & 30.3 & 34.8 & * & $4.5(-0.0$ to 9.1$)$ & * & * \\
\hline At least one of $D$ pteronyssinus, rye grass, Alternaria & * & 38.7 & 45.4 & * & $6.7(2.2$ to 11.2$)$ & * \\
\hline D pteronyssinus & $\star$ & 18.6 & 30.3 & * & $11.7(7.7$ to 15.6$)$ & * \\
\hline Rye grass & 22.0 & 23.8 & 28.8 & $0.8(-3.2$ to 4.9$)$ & $6.0(2.0$ to 10.0$)$ & $6.8(2.7$ to 10.9$)$ \\
\hline Alternaria & 13.0 & 15.4 & 20.4 & $2.4(-1.0$ to 5.8$)$ & $5.0(1.4$ to 8.5$)$ & $7.4(3.9$ to 10.9$)$ \\
\hline
\end{tabular}

^No value because the concentration or source of allergens were not the same between studies.

Respiratory Medicine. ${ }^{89}$ Between study comparisons were made using questions that were identical and included "Has your child ever wheezed?" followed by "if yes, was this in the past 12 months?"; "Has your child ever been diagnosed as having asthma by a doctor or at a hospital?"; "Has your child ever taken any medicine for asthma?"; "Has the child's natural mother ever had asthma?"; and "Has your child ever had attacks of hay fever or nasal allergies". The question "Is your child of Aboriginal or Torres Strait Islander origin?" derived from the Australian Bureau of Statistics 1996 census questionnaire was added to the 1997 respiratory questionnaire. This was used to determine the external validity of the sample of children selected from the population of children in the same age group in the whole of Wagga.

\section{ALLERGIC SENSITISATION}

In each study, allergic sensitisation was measured by skin prick test reactions to droplets of allergens placed on the forearm. ${ }^{10}$ The selection and number of allergens varied between studies but sensitisation to rye grass pollen (concentration $1 / 20 \mathrm{wt} / \mathrm{vol}$ ), the fungus Alternaria tenuis $(1 / 10 \mathrm{wt} / \mathrm{vol})$, cat dander (concentration 1/10 wt/vol in 1992 and 10000 $\mathrm{BAU} / \mathrm{ml}$ in 1997) and house dust mite were always tested. Rye grass pollen and Alternaria allergens were the only allergens where the concentration and source of the allergens were the same in all three studies. Sensitisation to house dust mite allergen was measured using Dermatophgoides farinae $(1 / 50 \mathrm{wt} / \mathrm{vol})$ in 1982 and 1992, and using the standardised allergen $D$ pteronyssinus (30 $000 \mathrm{AU} / \mathrm{ml}$ ) in 1992 and 1997. All allergens were purchased through Hollister-Stier and manufactured at the same plant (Bayer Corporation, PO Box 3145, Spokane, WA 99220-3145, USA). Histamine $(10 \mathrm{mg} / \mathrm{ml})$ was used as the positive control and a normal saline/glycerol solution as the negative control.

Skin wheal size was recorded as the mean of the length of the long axis to the wheal and the length of its perpendicular. Size was recorded at 10 minutes after skin prick in 1982, at 10 and 15 minutes in 1992, and at 15 minutes in 1997. A mean wheal size of $3 \mathrm{~mm}$ or more was coded as a positive response. Comparison of the 1992 results at 10 and 15 minutes enabled the prevalence of allergic sensitisation in 1982 to be adjusted so that it was equivalent to a prevalence measured at 15 minutes in $1992 .^{2}$ Children were classified as atopic if they had a positive response to one or more of the allergens tested.

\section{STATISTICAL ANALYSIS}

Analyses comparing 1982 and 1992 data were made using the statistical program SAS (SAS Institute 1985, Version 5, Cary, New Carolina). The analyses of the 1997 data were undertaken using STATA (StataCorp., Stata Statistical Software Release 6.0, 1997, Stata Corporation, College Station, Texas). $\chi^{2}$ tests were used to determine the significance of differences in proportions and to test for significance of trend over time.

\section{Results}

The number of children studied was 769 in 1982 ( $51 \%$ boys), 850 in 1992 (54\% boys), and 1016 (52\% boys) in 1997. The response rates were $88 \%$ for both questionnaires and skin prick tests in $1982,83 \%$ and $79 \%$ respectively in 1992 , and $71 \%$ and $67 \%$ respectively in 1997. Five per cent of children in the 1997 study were reported as being of Aboriginal or of Torres Strait Islander origin by their parents. This is similar to the proportion for indigenous children of the same age registered in the census in Wagga Wagga in 1996 (4.8\%, 95\% confidence interval (CI) 4.1 to $5.6 \%) .{ }^{11}$

The prevalence of wheeze, asthma diagnosis, and use of asthma medicine increased two- to threefold between 1982 and 1997 ( $p<0.001$ for trend; see table 1). The prevalence of hay fever and nasal allergies increased between 1982 and 1992 but was the same in 1992 and 1997. There was an increase in the proportion

Table 3 Change in prevalence (\%) of symptoms in atopic * and non-atopic children, 1992-1997

\begin{tabular}{|c|c|c|c|c|c|c|c|c|}
\hline \multirow[b]{2}{*}{ Symptoms } & \multicolumn{2}{|l|}{1992} & \multicolumn{2}{|l|}{1997} & \multicolumn{2}{|c|}{ Percent increase 1992-97 (95\% CI) } & \multicolumn{2}{|c|}{$\begin{array}{l}\text { Proportionalt increase } \\
1992-97\end{array}$} \\
\hline & $\begin{array}{l}\text { Atopic \% } \\
(n=301)\end{array}$ & $\begin{array}{l}\text { Non-atopic \% } \\
(n=540)\end{array}$ & $\begin{array}{l}\text { Atopic \% } \\
(n=436)\end{array}$ & $\begin{array}{l}\text { Non-atopic \% } \\
(n=519)\end{array}$ & Atopic & Non-atopic & Atopic & Non-atopic \\
\hline $\begin{array}{l}\text { Wheezed in the past } 12 \\
\text { months }\end{array}$ & 37.9 & 13.3 & 39.2 & 16.6 & $1.4(-5.8$ to 8.5$)$ & $3.2(-1.1$ to 7.5$)$ & 3.6 & 24.2 \\
\hline Diagnosed asthma & 46.3 & 21.6 & 47.4 & 31.3 & $1.0(-6.3$ to 8.4$)$ & 9.7 (4.4 to 15.0$)$ & 2.2 & 44.9 \\
\hline Ever had asthma medicine & 49.8 & 26.8 & 56.0 & 37.7 & $6.1(-1.2$ to 13.5$)$ & $10.9(5.3$ to 16.5$)$ & 12.2 & 19.5 \\
\hline
\end{tabular}

*Atopic to at least one of $D$ pteronyssinus, rye grass, Alternaria

$\dagger$ Proportional increase $=((1997$ prevalence -1992 prevalence $) / 1992$ prevalence $) \times 100$. 
of parents who reported having asthma over the whole time period.

There was a significant increase in prevalence of atopy between 1992 and 1997, although the increase between 1982 to 1992 had been non-significant (see table 2). Sensitisation to Alternaria and rye grass pollen increased by $5 \%$ and $6 \%$ respectively during the 15 year time period $1982-1997$ ( $p<0.001$ for trend).

Comparisons of the increases in prevalence of wheeze and asthma diagnosis between 1992 and 1997 between children atopic to at least one of $D$ pteronyssinus, rye grass, and Alternaria, and in non-atopic children showed that the proportional increases were smaller for the children classified as atopic (see table 3 ). The same trend was also seen for medication use which increased to a greater extent in nonatopic compared to atopic children.

\section{Discussion}

We found that the trend for an increase in the prevalence of asthma and atopy reported for the decade 1982-92 continued to 1997. Importantly, this has been one of the first studies to monitor increases in the prevalence of atopy using objective measurements over a long period of time. In 1997, more than 1 in 4 children were reported to have wheezed in the previous year, almost 4 in 10 had been diagnosed as having asthma, and almost 1 in 2 children had used a medicine for asthma. These figures are surprisingly high and confirm the value of ongoing surveillance studies such as these which incorporate objective measurements to monitor trends in asthma and atopy.

The same standard methods were used to measure symptoms and atopy in the studies. It is unlikely that sample bias substantially affected our estimates of prevalence. In 1982 and 1992, the study participants were from schools selected at random throughout the town. In 1997, only children from schools in western Wagga were selected, but the comparison with the 1996 census showed that this sample was likely to be representative of children in Wagga Wagga. Eleven year old children were not included in the 1982 study, but the prevalence of outcomes in this age group were similar to those found in $8-10$ year olds. ${ }^{12}$

The response rates from schools were higher in 1982 and 1992 than in 1997. If parents of children with asthma were more likely to enter their child into the studies, we will have over estimated the size of the increase since 1982 . The proportion of parents who had been diagnosed with asthma also increased over the time period. This is consistent with the increase in the prevalence of asthma in young adults which has been reported elsewhere, ${ }^{3}{ }^{13}$ but it is possible that parents with asthma were more likely to enrol their child into the study. The true prevalence of "wheeze in the past 12 months" in 1997 could lie between the lower confidence limit, calculated on the assumption that all non-participating children did not have asthma $(19.2 \%)$, and the upper limit, calculated on the assumption that all non-participating children have asthma (48.2\%). However, comparison with other studies suggests that bias this extreme is unlikely. The prevalence of "wheeze in the past 12 months" in children was measured in four Australian cities in 1993-94 for the International Study of Allergies and Asthma in Childhood. ${ }^{14}$ The prevalence in 10914 children aged 6-7 years and 12280 children aged 13-14 years in Melbourne, Sydney, Adelaide, and Perth in $1993 / 94$ was $24.6 \%$ (95\% CI 23.8 to 25.5 ) and $29.4 \%$ (95\% CI 28.6 to 30.2 ) respectively. These results are similar to the prevalence of wheeze in our study of $27.7 \%$. In addition, the mean annual increase in the prevalence of wheeze in the past year was $0.8 \%$ which is within the range of annual increases reported for other comparisons of serial cross sectional surveys. ${ }^{1}$

In this study we were able to standardise the methods used for measuring atopy, and comparison was restricted to allergens manufactured at the same plant to the same concentration. The concentration of $D$ pteronyssinus has been subject to additional quality control procedures and has been licensed as a standardised product in the USA since 1988 (letter from Bayer Australia Ltd, 21/01/2000); the prevalence of sensitisation to this allergen increased by $11.7 \%$ between 1992 and 1997 . Overall there was a non-significant increase in prevalence of atopy between 1982 and 1992 and a significant increase between 1992 and 1997. In contrast, the prevalence of hay fever increased significantly between 1982 and 1992 but remained the same between 1992 and 1997. There has been one report in the peer reviewed literature of the change in prevalence of atopy measured by skin prick test between cross sectional studies. ${ }^{5}$ In this report of two cross sectional studies in Leipzig in former east Germany, the prevalence of atopy in children aged 9-11 years increased from $19.3 \%$ in $1991-92$ to $26.7 \%$ in $1995-96$ ( $p<0.0001)$. The prevalence of hay fever reported by questionnaire also increased over the time period. These increases were attributed to the introduction of a western lifestyle into Leipzig after unification.

Recent increases in the prevalence of asthma and allergic diseases have been attributed to environmental changes to lifestyle. Although we did not collect information about change in allergen exposure between 1992 and 1997, we found a 4.5 -fold increase in the mean numbers of house dust mites in dust samples from homes in Wagga Wagga between 1982 and 1992. ${ }^{7}$ Dietary changes in western societies such as the decreased consumption of fresh fruit and vegetables and increased consumption of polyunsaturated fatty acids may affect the immune response and are another possible explanation. ${ }^{215}$ It is also possible that the decline in infection rates among infants in western societies has had a detrimental effect on the development of the immune system and increased the likelihood of the development of an atopic response, ${ }^{2}{ }^{16}$ although it is not a cause for the increase in asthma in non-atopic children.

We found that the proportional increases in wheeze in the past 12 months and asthma 
diagnosis were greater for non-atopic than for atopic children between 1992 and 1997 . Increased exposure to early childhood infections has been strongly associated with an increased risk of asthma in non-atopic children. ${ }^{17}$ However, there is no evidence that the incidence of early childhood infection changed in Wagga Wagga between 1992 and 1997.

In this further cross sectional study, we were able to show that the increasing prevalence of asthma and atopy that was identified in the 1980s has continued in the past decade, so that a high proportion of children now experience respiratory symptoms. This has important implications for the health of future generations of children, and continues to reinforce the message that prevention programmes are needed.

We thank the children, parents, and school staff in Wagga Wagga for enabling us to undertake the study. We also thank Robyn Paton, Margi Jones, Ann Maine, and Peter Hansen who helped us collect the data. This work was supported by the National Health and Medical Research Council, Australia and Glaxo Allen+Hanburys.

1 Magnus P, Jaakkola JJK. Secular trend in the occurrence of asthma among children and young adults: critical appraisal of repeated cross-sectional surveys. BMF 1997;314:17959.

2 Howarth PH. Is allergy increasing? Early life influences. Clin Exp Allergy 1998;28(suppl 6):2-7.

3 Hopper JL, Jenkins MA, Carlin JB, Giles CG. Increase in the self-reported prevalence of asthma and hay fever in adults over the last generation: a matched parent-offspring study. Aust F Public Health 1995;19:120-4.
4 Nina TK, Russell G. Respiratory symptoms and atopy in Aberdeen school children: evidence from two surveys 25 Aberdeen school children: evidence
years apart. BMF 1992;304:873-5.

5 von Mutius E, Weiland SK, Fritzsch C, Duhme H, Keil U. Increasing prevalence of hay fever and atopy among children in Leipzig, East Germany. Lancet 1998;351:862-6.

6 Robertson CF, Heycock E, Bishop J, Nolan T, Olinsky A, Phelan P. Prevalence of asthma in Melbourne schoolchildren: changes over 26 years. BMf 1991;302: 1116-18.

7 Peat JK, van den Berg RH, Green WF, Mellis CM, Leeder SR, Woolcock AJ. Changing prevalence of asthma in Australian children. BMF 1994;308:1591-6.

8 Peat JK, Salome CM, Toelle BG, Bauman A, Woolcock AJ. Reliability of a respiratory questionnaire and effect of mode of administration on classification of asthma in children. Chest 1992;102:153-7.

9 Salome CM, Peat JK, Britton WJ, Woolcock AJ. Bronchial hyperresponsiveness in two populations of Australian schoolchildren. Relation to respiratory symptoms and diagnosed asthma. Clin Allergy 1987;17:271-81.

10 Pepys J. Skin testing. Br f Hosp Med 1975;14:412-17.

11 Australian Bureau of Statistics. Clib96. The 1996 Census of Population and Housing. 1998.

12 Peat JK, Toelle BG, Gray EJ, et al. Prevalence and severity of childhood asthma and allergic sensitisation in seven climatic regions of New South Wales. Med f Aust 1995;163:22-6.

13 Weiss KB. An overview of recent trends in asthma epidemiology. Eur Respir Rev 1996;6:101-4.

14 Robertson CF, Dalton MF, Peat JK, et al. Asthma and other atopic diseases in Australian children. Med $\mathcal{F}$ Aust 1998; 168:434-8.

15 Steerenberg PA, Van Amsterdam JGC, Vandebriel RJ, Vos JG, Van Bree L, Van Loveren H. Environmental and lifestyle factors may act in concert to increase the prevalence of respiratory allergy including asthma. Clin Exp prevalence of respiratory

16 Martinez FD. Gene by environment interactions in the development of asthma. Clin Exp Allergy 1998;28:21-5.

17 von Mutius E, Illi S, Hirsch T, Leupold W, Keil U, Weilan SK. Frequency of infections and risk of asthma, atopy and airway hyper-responsiveness in children. Eur Respir f 1999; 14:4-11.

\section{2nd World Congress of the Pediatric Thoracic Disciplines}

\section{April 26-8, 2000; Izmir, Turkey}

Further details: Prof Dr Oktay Mutaf, Ege University Faculty of Medicine, Pediatric Surgery Department. Fax: +90 232 3751288; email: omutaf@med.rgr.rdu.tr 